Article

\title{
Candida-Acinetobacter-Pseudomonas Interaction Modelled within 286 ICU Infection Prevention Studies
}

\author{
James C. Hurley \\ Rural Health Academic Center, Melbourne Medical School, University of Melbourne, Ballarat 3350, Australia; \\ jamesh@bhs.org.au
}

Received: 31 July 2020; Accepted: 21 October 2020; Published: 27 October 2020

check for updates

\begin{abstract}
Background: Whether Candida interacts to enhance the invasive potential of Acinetobacter and Pseudomonas bacteria cannot be resolved within individual studies. There are several anti-septic, antibiotic, anti-fungal, and non-decontamination-based interventions to prevent ICU acquired infection. These effective prevention interventions would be expected to variably impact Candida colonization. The collective observations within control and intervention groups from numerous ICU infection prevention studies simulates a multi-centre natural experiment with which to evaluate Candida, Acinetobacter and Pseudomonas interaction (CAPI). Methods: Eight Candidate-generalized structural equation models (GSEM), with Candida, Pseudomonas and Acinetobacter colonization as latent variables, were confronted with blood culture and respiratory tract isolate data derived from $>400$ groups derived from 286 infection prevention studies. Results: Introducing an interaction term between Candida colonization and each of Pseudomonas and Acinetobacter colonization improved model fit in each case. The size of the coefficients (and 95\% confidence intervals) for these interaction terms in the optimal Pseudomonas (+0.33; 0.22 to 0.45$)$ and Acinetobacter models (+0.32; 0.01 to 0.5$)$ were similar to each other and similar in magnitude, but contrary in direction, to the coefficient for exposure to topical antibiotic prophylaxis (TAP) on Pseudomonas colonization $(-0.45 ;-0.71$ to -0.2$)$. The coefficient for exposure to topical antibiotic prophylaxis on Acinetobacter colonization was not significant. Conclusions: GSEM modelling of published ICU infection prevention data supports the CAPI concept. The CAPI model could account for some paradoxically high Acinetobacter and Pseudomonas infection incidences, most apparent among the concurrent control groups of TAP studies.
\end{abstract}

Keywords: Candida; bacteraemia; Acinetobacter; Pseudomonas; study design; intensive care; mechanical ventilation; generalized structural equation model

\section{Introduction}

Candida colonization at the respiratory tract and elsewhere is associated with poor outcomes among high-risk ICU patients [1]. The reason for this association remains unclear as Candida itself is a rare cause of ventilator-associated pneumonia (VAP) and candidemia occurs infrequently in the ICU $[2,3]$. Several preclinical studies have implicated a potential interaction between Candida colonization and invasive infection with Gram-negative bacilli including Pseudomonas and Acinetobacter bacteria [4].

Defining the clinical relevance of the postulated Candida-Acinetobacter-Pseudomonas interaction (CAPI) is unlikely to be achieved within the constraints of a single centre study as there are several obstacles. Moreover, measuring colonization and quantifying the impact of the various interventions on it is not simple [5]. However, the collective observations within control and intervention groups from numerous ICU infection prevention studies simulates a multi-centre natural experiment of Candida colonization subject to various exposures and provides an opportunity to evaluate CAPI. 
The prevention of VAP and other ICU acquired infections is of great interest and various anti-septic, antibiotic, anti-fungal, or non-decontamination-based interventions have been studied [6-26]. These methods variably target colonization with Gram-negative bacteria such as Pseudomonas and Acinetobacter bacteria and also Candida [26,27]. Topical antibiotic prophylaxis (TAP)-based methods appear to be the most effective for the overall prevention of VAP and bacteraemia among ICU patients [27]. Surprisingly, the incidences of infection with Candida [28,29] and likewise incidences of both Acinetobacter [30] and Pseudomonas bacteraemia [31] are unusually high among studies of methods using TAP. This is both paradoxical, as topical amphotericin, polymyxin and aminoglycosides are common TAP constituents, and unexplained.

The objective here is to develop candidate generalized structural equation models (GSEM) founded on CAPI concepts and then confront these models using group-level infection data from published studies of ICU patient groups being subject to various group-level exposures.

\section{Materials and Methods}

Being an analysis of published work, ethics committee review of this study was not required.

\subsection{Study Selection and Decant of Groups}

The literature search and study decant used here is as in Figure 1. Twenty-three systematic reviews and meta-analyses were used as the starting point as these provided evidence base of the interventions of interest [1,5-26]. A snowballing search strategy [32] using the "Related articles" function within Google Scholar was undertaken for additional studies not identified within key systematic reviews. The key inclusion and exclusion criteria described previously [27], being a patient group requiring prolonged ( $>24 \mathrm{~h}$ ) ICU stay with group-level data for any of Pseudomonas or Acinetobacter infection data available, was expanded to include Candida infection data and studies of single anti-fungal prophylaxis $[28,29]$. All eligible studies were then collated, and any duplicate studies were removed.

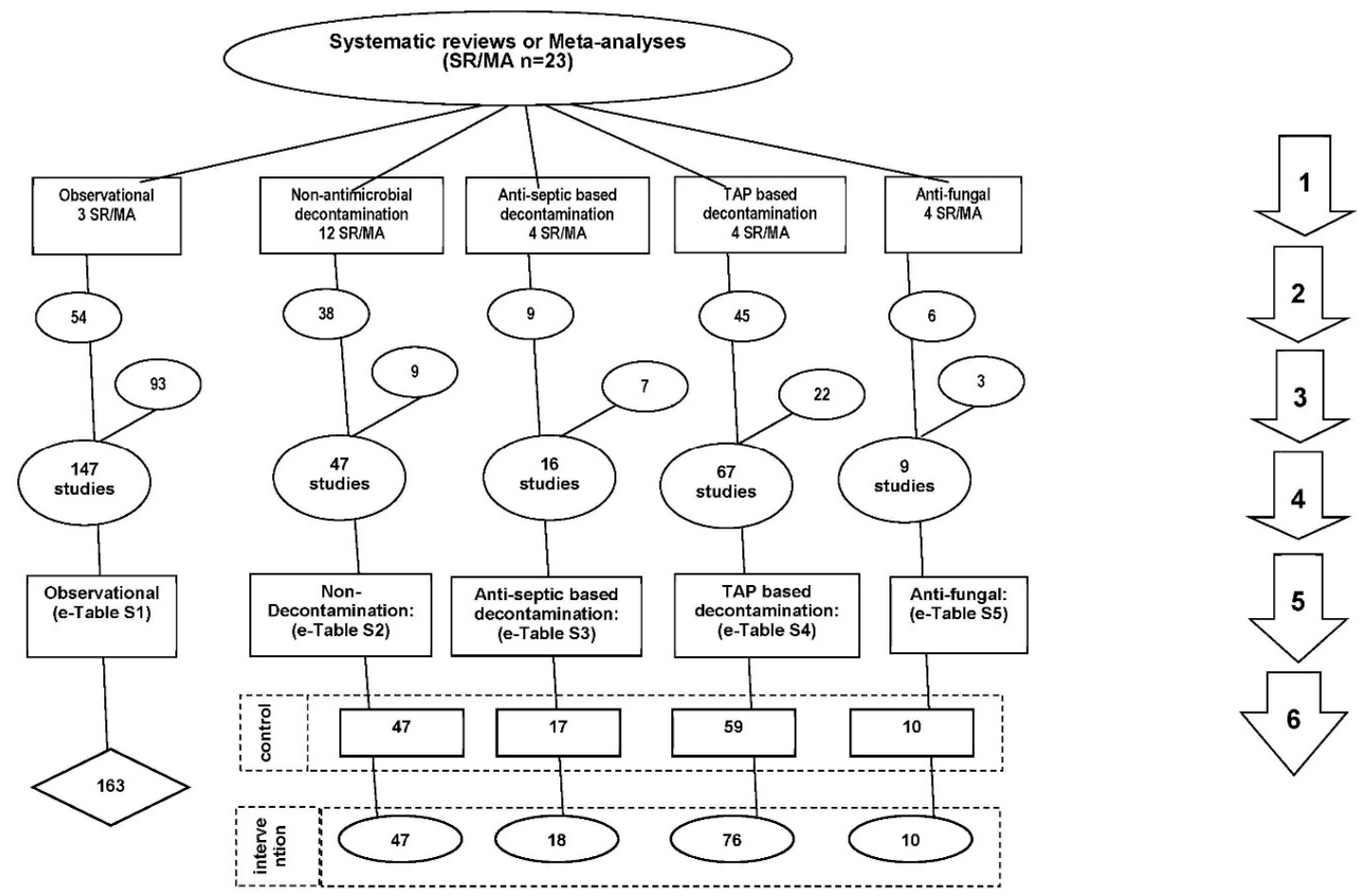

Figure 1. Search method, screening criteria and resulting classification of eligible studies and subsequent decant of component groups. The four numbered arrows are as follows; An electronic search for systematic 
reviews or meta-analysis (SR/MA) containing potentially eligible studies using search terms; "ventilator associated pneumonia", "mechanical ventilation", "intensive care unit", each combined with either "meta-analysis" or "systematic review" up to December 2018. The systematic reviews were then searched for studies of patient populations requiring prolonged ( $>24 \mathrm{~h}$ ) ICU admission; The studies were triaged from the systematic reviews into one of five categories; studies in which there was no intervention (observational studies), studies of various non-decontamination methods such as methods delivered either via the gastric route, the airway route or via the oral care route, studies of anti-septic methods, studies with a TAP-based (in any formulation) intervention, and studies of antifungal prophylaxis as a single agent. All studies were reviewed for potentially eligible studies and screened against inclusion and exclusion criteria. Any duplicate or ineligible studies were removed and studies identified outside of systematic reviews were included. The component groups were decanted from each study being control (rectangles), intervention (ovals) and observation (diamond) groups. Note: the total numbers do not tally as some systematic reviews provided studies in more than one category and some studies provided groups in more than one category and some studies have unequal numbers of control and interventions groups. Abbreviations; TAP = Topical antibiotic prophylaxis; ICU = Intensive Care Unit; SR/MA = systematic reviews or meta-analysis.

In the GSEM modelling, the Candida, Pseudomonas and Acinetobacter infection data serve as the measurement components, the group-level exposure parameters serve as the structural components and colonization with Candida, Pseudomonas and Acinetobacter, each represented as latent variables, link the structural and measurement components.

\subsection{Measurement Components}

The incidences of Pseudomonas and Acinetobacter VAP as well as the incidences of Pseudomonas and Acinetobacter bacteraemia were extracted. As Candida is generally not thought to be a cause of VAP, the count of Candida as a respiratory tract (RT Candida) isolate among patients with suspected VAP was recorded along with counts of candidemia. Counts for all subspecies of Candida, Pseudomonas and Acinetobacter were included. These were each expressed as a proportion using the number of patients with a prolonged $(>24 \mathrm{~h}$ ) stay in the ICU as the denominator.

\subsection{Structural Components}

The following data were extracted and used to form the structural components of the models; year of study publication, whether the majority of the group were trauma patients, whether more than $90 \%$ of patients of the group received more than $24 \mathrm{~h}$ of MV, and whether the mean (or median) length of ICU stay for the group was less than five, five to ten days, or more than ten days. In the extraction of MV percentages, if this was not stated for any group, a percentage less than $90 \%$ was assumed. In the extraction of ICU length of stay (ICU-LOS) data from the studies, surrogate measures including mean (or median) length of mechanical ventilation were taken if the length of ICU-LOS was not available in order to generate broad categories of ICU stay of less than 5 days, 5 to 10 days and more than 10 days.

Additionally, the presence of any of the following group wide risk factors for candidemia and invasive Candida infection were noted including liver transplantation or liver failure, use of parenteral nutrition, surgery for intestinal perforation, pancreatitis and being colonized with Candida, regardless of how Candida colonization was defined. An anti-septic exposure included use of agents such as chlorhexidine, povidone-iodine and iseganan. All anti-septic exposures were included regardless of whether the application was to the oropharynx, by tooth-brushing or by body-wash.

Topical antibiotic prophylaxis (TAP) is defined here as the group wide application of topical antibiotics to the oropharynx or stomach without regard to the specific antibiotic constituents. Protocolized parenteral antibiotic prophylaxis (PPAP) is the group wide use of any parenteral antibiotic used on a prophylactic basis. Group wide exposure to anti-fungal prophylaxis was identified whether this was as a single agent, or as part of a multi-agent decontamination regimen such as within selective digestive decontamination, without regard to the specific anti-fungal agent. 


\subsection{Structural Equation Modelling}

Eight candidate GSEM models were developed with Candida colonization and either Pseudomonas (four models; models 1 to 4 ) or Acinetobacter colonization (four models; models 5 to 8 ) as the latent variables intermediary between the structural and measurement components. The models were constructed with (models 1, 2, 5 and 6) and without (models 3, 4, 7 and 8) the inclusion of studies with group mean length of ICU stay less than 5 days and with (models 2, 4, 6 and 8) and without (models 1, 3,5 and 7) an interaction term between the Candida colonization and respectively the Pseudomonas and Acinetobacter colonization latent variables.

As the observations are clustered by study, in each model, a study identifier was used in order to generate a robust variance covariance matrix of the parameters of each coefficient estimate. The GSEM model with the lowest Akaike's information criterion (AIC) score was selected as having parsimony and optimal fit from among the candidate models using the "GSEM" command in Stata [33].

\subsection{Visual Benchmarking}

Scatter plots of the Candida, Pseudomonas and Acinetobacter infection data were generated to facilitate a visual survey of the entire data as derived from the literature. To facilitate this visual survey, a benchmark for each outcome of interest was generated from the groups of the observational studies as described previously [27].

\subsection{Availability of Data and Materials}

All data generated or analysed during this study are included in this published article and its supplementary information files (see Electronic Supplementary Materials; ESM).

\section{Results}

\subsection{Characteristics of the Studies}

Of the 286 studies identified by the search, 135 were sourced from 23 systematic reviews (Table 1, ESM Tables S1-S5). Others were found during previous searches or by snowball sampling (ESM Figure S1). Most studies were published between 1990 and 2010 and most had a mean ICU-LOS exceeding ten days. A minority originated from either North American or trauma ICU's. Twelve studies had more than one type of intervention group and eight studies had no control group. The majority of groups from studies of infection prevention interventions had less than 150 patients per group whereas most of the observational studies had more than 150 patients per group.

Of the 286 studies, there were 23 groups from 12 studies having a group mean ICU-LOS less than 5 days including the largest ( $>120,000$ patients), which was a study of targeted versus universal decontamination versus standard care [34].

There was inequality in the numbers of infection prevention exposures. The majority of studies of anti-fungal exposure occurred within an exposure to combined TAP and anti-fungals in the context of a Selective Digestive Decontamination (SDD) regimen for which the antifungal used was topical amphotericin in 50 groups. The TAP exposures included either topical polymyxin or a topical aminoglycoside or both in every case except four intervention groups. PPAP, most commonly a cephalosporin, was used within ten control groups and 44 intervention groups of TAP studies. By contrast, anti-fungal prophylaxis used as a single agent (i.e., constituted without topical antibiotics) occurred in only nine groups and for most of these groups, the patient groups were selected on the basis of risk factors for invasive Candida infection. 
Table 1. Characteristics of studies ${ }^{a}$.

\begin{tabular}{|c|c|c|c|c|c|}
\hline & \multirow{2}{*}{$\begin{array}{c}\begin{array}{c}\text { Observational } \\
\text { Studies }\end{array} \\
\text { (No Intervention) }\end{array}$} & \multicolumn{4}{|c|}{ Infection Prevention Studies } \\
\hline & & Non-Decontamination & Anti-Septic & $\mathrm{TAP} \pm \mathbf{P P A P}$ & Anti-Fungal \\
\hline \multicolumn{6}{|l|}{ Study characteristics } \\
\hline \multirow{2}{*}{ Sources } & ESM & ESM & ESM & ESM & ESM \\
\hline & Table S1 & Table S2 & Table S3 & Table S4 & Table S5 \\
\hline Number of studies & 147 & 47 & 16 & 67 & 9 \\
\hline Origin from systematic review ${ }^{b}$ & 46 & 38 & 7 & 38 & 9 \\
\hline Study publication year (range) & 1987-2018 & 1987-2017 & 2000-2016 & 1984-2018 & 1994-2014 \\
\hline North American ICU's ${ }^{c}$ & 36 & 11 & 7 & 6 & 0 \\
\hline Trauma ICUs ${ }^{\mathrm{d}}$ & 24 & 10 & 3 & 15 & 0 \\
\hline \multicolumn{6}{|l|}{ Group characteristics } \\
\hline number of groups & 164 & 94 & 35 & 102 & 20 \\
\hline LOS $<5$ days & 10 & 0 & 8 & 6 & 0 \\
\hline LOS $>10$ days & 101 & 54 & 18 & 97 & 15 \\
\hline MV for $>48 \mathrm{~h}$ for $<90 \% \mathrm{e}^{\mathrm{e}}$ & 40 & 0 & 16 & 33 & 8 \\
\hline PPAP use in control group ${ }^{f}$ & 0 & 0 & 0 & 10 & 0 \\
\hline $\mathrm{CRF}^{\mathrm{g}}$ & 11 & 0 & 0 & 17 & 12 \\
\hline Numbers of patients per control group; & 279 & 75 & 130 & 61 & 65 \\
\hline$(\text { median; IQR })^{\mathrm{h}}$ & $118-604$ & 60-143 & $36-347$ & $318-123$ & $51-75$ \\
\hline
\end{tabular}

a. Note, several studies had more than one control and or intervention group. Hence the number of groups does not equal the number of studies. Abbreviations; TAP $=$ Topical antibiotic prophylaxis; PPAP $=$ Protocolized parenteral antibiotic prophylaxis; ICU = Intensive Care Unit; ESM = electronic supplemental material (web-only supplement); LOS = length of stay; MV = mechanical ventilation. ${ }^{b}$. Studies that were sourced from 16 systematic reviews (references in web-only supplement) ${ }^{\text {c. }}$ Study originating from an ICU in Canada of the United States of America.

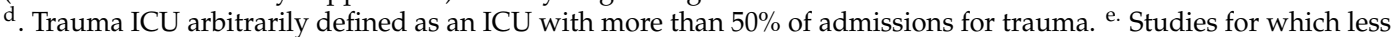
than $90 \%$ of patients were reported to receive $>48 \mathrm{~h}$ of MV. ${ }^{\mathrm{f}}$. Use of PPAP for control group patients. ${ }^{g}$. CRF is risk factors for Candidemia or invasive Candida infection such as patient groups selected on the basis of Candida colonization. ${ }^{\text {h. }}$ Data is median and inter-quartile range (IQR).

\subsection{Infection Data}

Across all intervention categories among groups with non-zero counts, the incidences for RT Candida (Figure 2a) and Candidemia (Figure 2b) and Pseudomonas VAP (Figure 3a) and bacteraemia (Figure $3 b$ ) and Acinetobacter VAP (Figure 4a) and bacteraemia (Figure 4b) in each case varied by $>100$ fold, ranging approximately ten-fold above and tenfold below the respective literature derived benchmark. In general, the mean incidence among each category of intervention group was up to $60 \%$ lower than the mean in the corresponding category of control group (Figures 2-4).

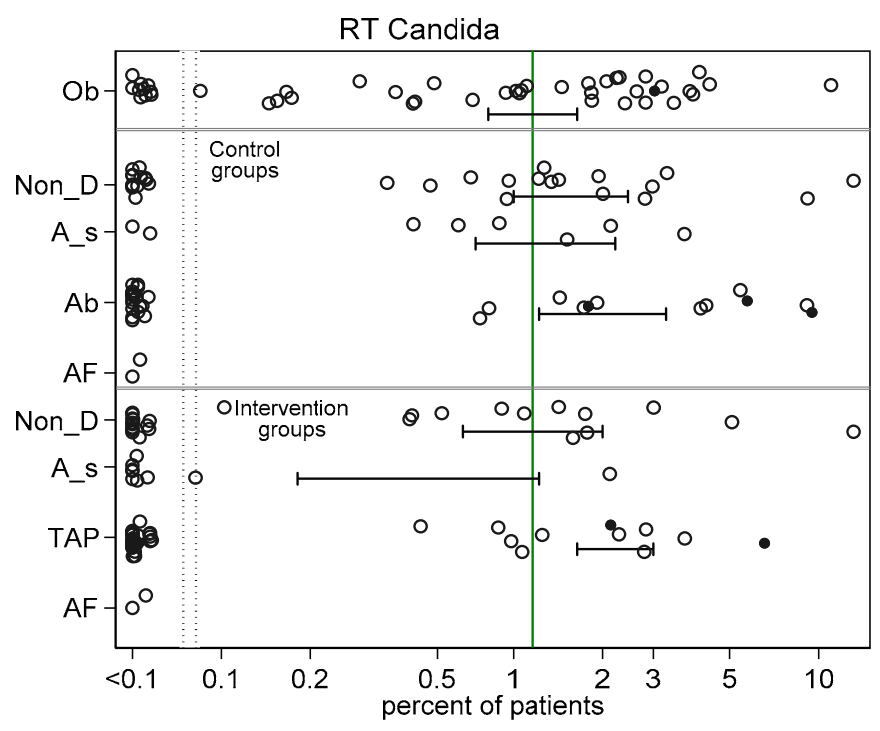

(a)

Figure 2. Cont. 


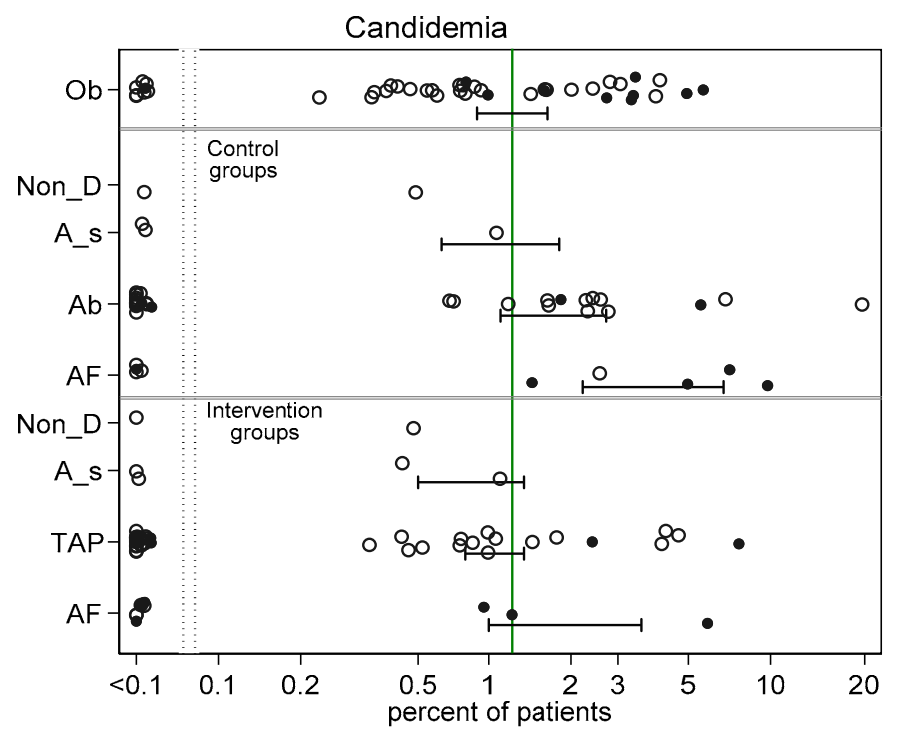

(b)

Figure 2. Scatter plots (logit scale) and 95\% CI of RT Candida incidence (a) and Candidemia (b) in component (control and intervention) groups of various methods of infection prevention in the ICU, excluding studies with ICU-LOS $<5$ days (ESM Figure S2a,b show including studies with ICU-LOS $<5$ days). The benchmark incidence in each plot is the summary mean derived from the observation studies (central vertical line). The groups wide presence of candidemia risk factors (CRF) is identified by solid symbols versus not (open). Abbreviations; $\mathrm{Ob}=$ observational; non-D is non-decontamination; A_s is anti-septic; $\mathrm{Ab}$ is antibiotic control group; TAP is topical antibiotic prophylaxis and AF is anti-fungal.

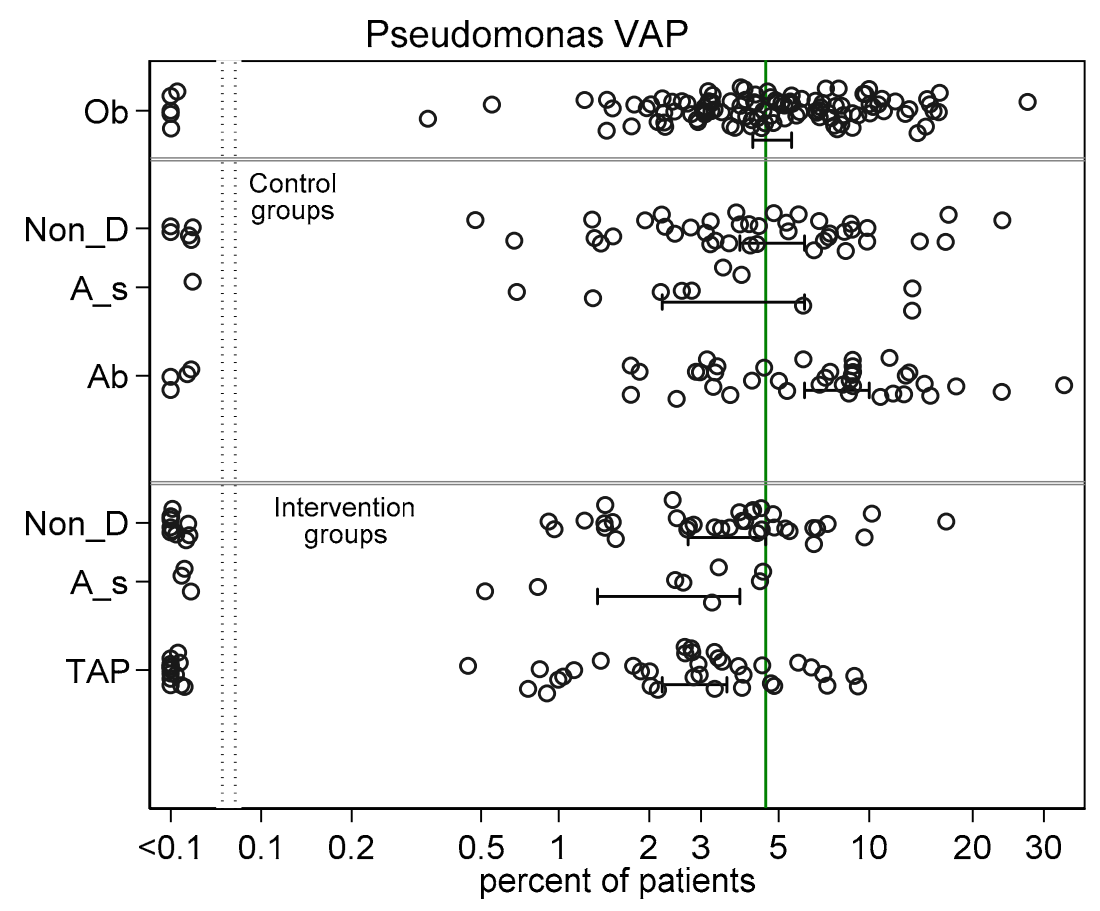

(a)

Figure 3. Cont. 


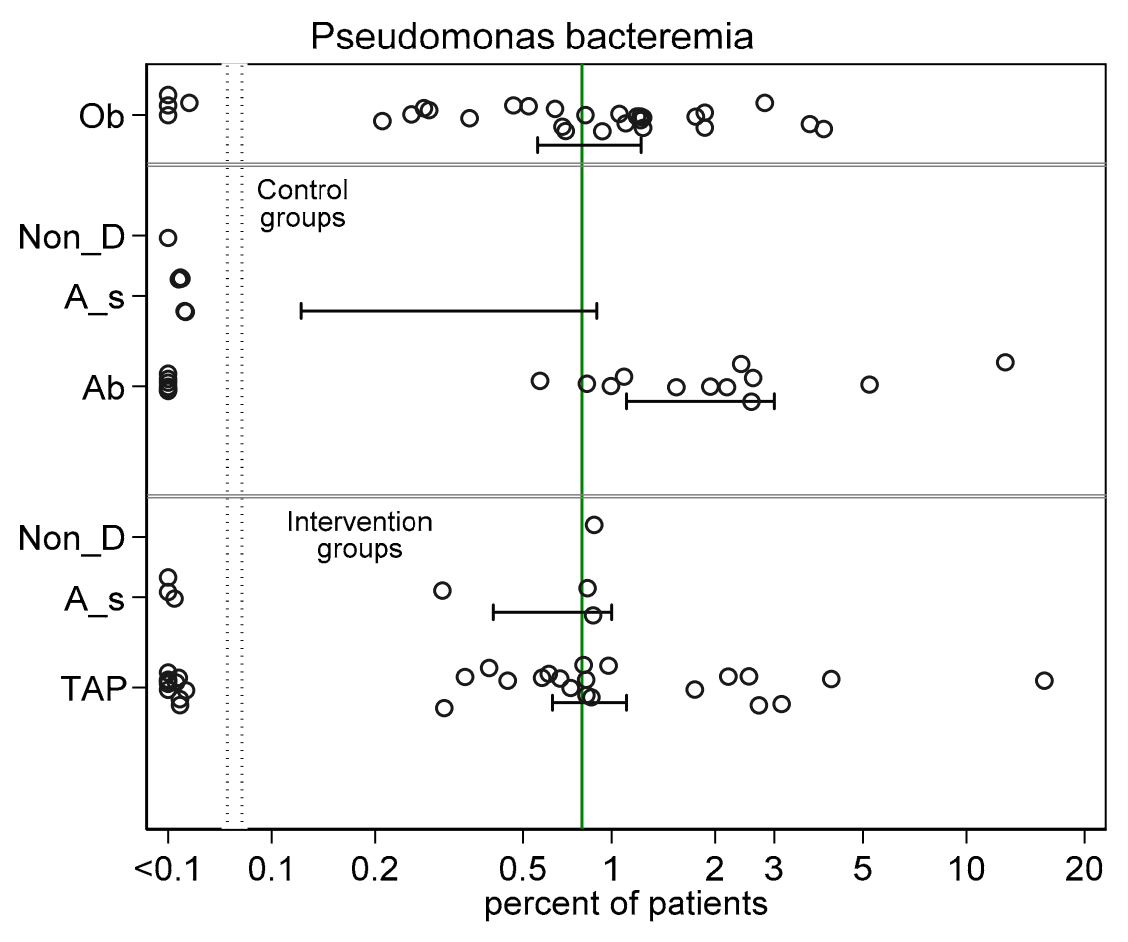

(b)

Figure 3. Scatter plots (logit scale) and 95\% CI of Pseudomonas VAP incidence (a) and Pseudomonas bacteraemia (b) in component (control and intervention) groups of various methods of infection prevention in the ICU, excluding studies with ICU-LOS $<5$ days (ESM Figure S3a,b show including studies with ICU-LOS $<5$ days). The benchmark incidence in each plot is the summary mean derived from the observation studies (central vertical line). Abbreviations; $\mathrm{Ob}=$ observational; non-D is non-decontamination, A_s is anti-septic; Ab is antibiotic control group; TAP is topical antibiotic prophylaxis.

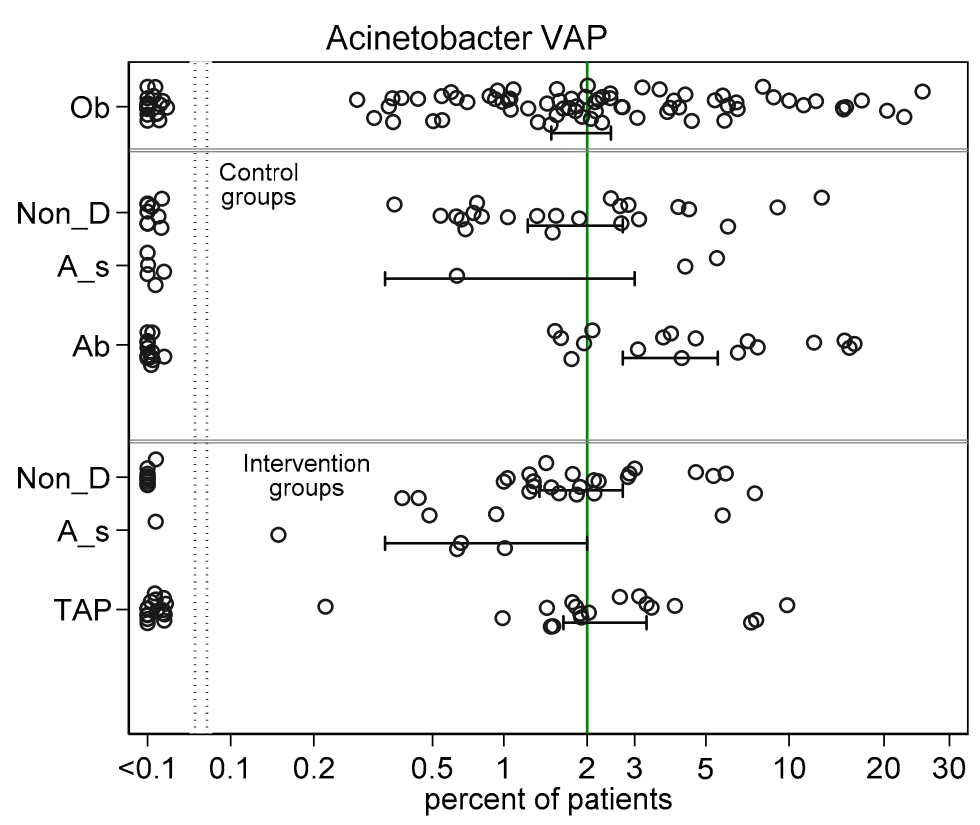

(a)

Figure 4. Cont . 


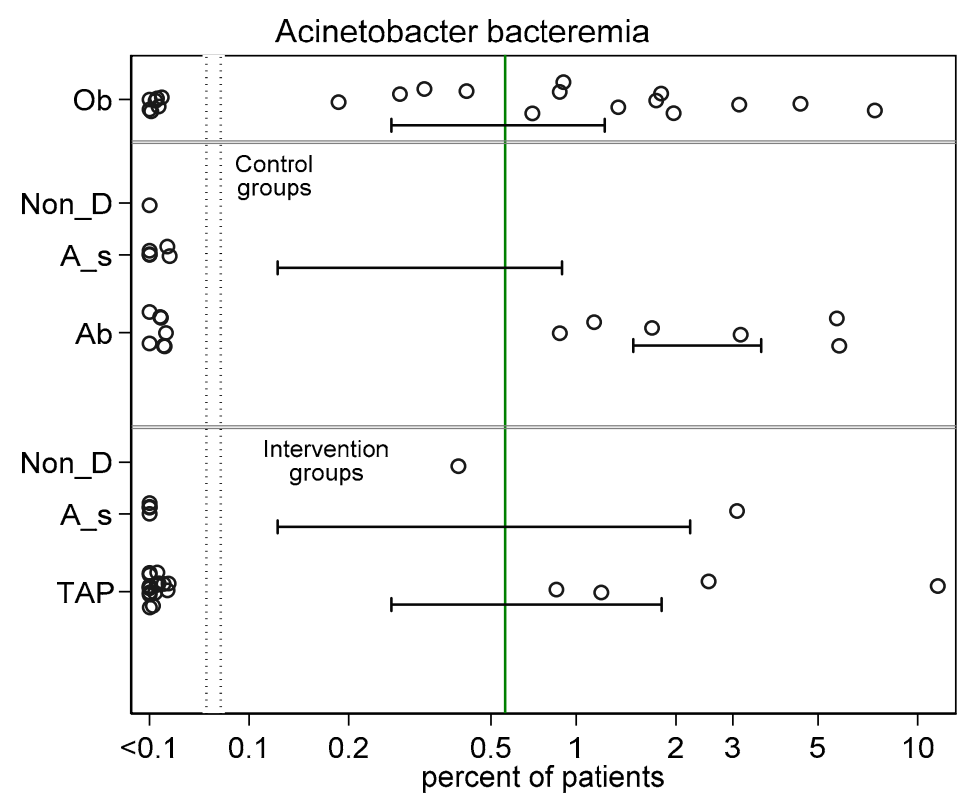

(b)

Figure 4. Scatter plots (logit scale) and 95\% CI of Acinetobacter VAP incidence (a) and Acinetobacter bacteraemia (b) in component (control and intervention) groups of various methods of infection prevention in the ICU, excluding studies with ICU-LOS $<5$ days (ESM Figure S4a,b show including studies with ICU-LOS $<5$ days). The benchmark incidence in each plot is the summary mean derived from the observation studies (central vertical line). Abbreviations; $\mathrm{Ob}=$ observational; non-D is non-decontamination; A_s is anti-septic; Ab is antibiotic control group; TAP is topical antibiotic prophylaxis.

The mean control and intervention group incidences of infection for VAP and bacteraemia for each of Pseudomonas (Figure 3) and Acinetobacter (Figure 4) were generally similar to the benchmark derived from observational groups with the following exceptions; the Pseudomonas VAP incidences among the antiseptic and TAP intervention groups were each approximately two percentage points below the Pseudomonas VAP benchmark and the mean incidences of infection for each of Pseudomonas (Figure 3) and Acinetobacter (Figure 4) for both VAP and bacteraemia among the control groups of TAP studies were each up to three percentage points higher than each benchmark.

\subsection{GSEM Modelling}

Eight candidate GSEM models were evaluated for fit and parsimony (see Table 2; ESM Figures S5-S8). In each case, the optimal model included an interaction term between the latent variables representing Candida colonization with either Pseudomonas colonization (Figure 5, ESM Figures S5 and S6) or Acinetobacter colonization (ESM Figures S7 and S8). The size of this interaction term was similar in magnitude and significant in each model. The inclusion (four models; Table 2) or not (four models; ESM Tables S6 and S7) of 23 groups that had mean ICU-LOS less than 5 days made no material difference to the findings. 
Table 2. Development of GSEM model ${ }^{a, b, c}$.

\begin{tabular}{|c|c|c|c|c|c|c|c|}
\hline \multicolumn{4}{|c|}{ Pseudomonas Models } & \multicolumn{4}{|c|}{ Acinetobacter Models } \\
\hline & Model 1 & & el 2 & & Model 5 & & el 6 \\
\hline & $\begin{array}{c}\text { Figure 5a and } \\
\text { Figure 55a }\end{array}$ & $\begin{array}{r}F \\
\text { and } E S\end{array}$ & $\begin{array}{l}e 5 b \\
\text { igure S5b }\end{array}$ & & ESM Figure S7a & ESI & are S7b \\
\hline & & & $95 \% \mathrm{CI}$ & & & & $95 \% \mathrm{CI}$ \\
\hline $\begin{array}{l}\text { Factor }{ }^{\mathrm{d}-\mathrm{i}} \\
\text { b_Ps_n }\end{array}$ & & & & $\begin{array}{l}\text { Factor }{ }^{\mathrm{d}-\mathrm{i}} \\
\text { b_Ac_n }\end{array}$ & & & \\
\hline $\begin{array}{l}\text { Pseudomonas } \\
\text { colonization }{ }^{j}\end{array}$ & $1.09 * * *$ & $1.10 * * *$ & 0.71 to 1.5 & $\begin{array}{l}\text { Acinetobacter } \\
\text { colonization } \mathrm{k}\end{array}$ & $1.18^{* * *}$ & $1.17 * * *$ & 0.92 to 1.4 \\
\hline ppap & $0.85^{* *}$ & 0.83 ** & 0.25 to 1.4 & ppap & 0.24 & 0.17 & -0.87 to 1.4 \\
\hline -cons & $-5.96^{* * *}$ & $-5.93 * * *$ & -6.8 to -5.1 & _cons & $-8.14^{* * *}$ & $-8.08 * * *$ & -9.2 to -6.9 \\
\hline $\begin{array}{c}\text { v_Ps_n } \\
\text { Pseudomonas }\end{array}$ & & & & $\mathrm{v} \_\mathrm{Ac} \_\mathrm{n}$ & & & \\
\hline $\begin{array}{l}\text { Pseudomonas } \\
\text { colonization }\end{array}$ & 1 & 1 & (constrained) & $\begin{array}{l}\text { Acinetobacter } \\
\text { colonization } \mathrm{k}\end{array}$ & 1 & 1 & (constrained) \\
\hline mvp90 & 0.36 & 0.32 & -0.04 to 0.7 & mvp90 & 0.58 & 0.54 & -0.12 to 1.3 \\
\hline non_D & $-0.50 * * *$ & $-0.49 * * *$ & -0.76 to -0.2 & non_D & -0.41 & -0.37 & -0.76 to 0.05 \\
\hline cons & $-4.33 * * *$ & $-4.31 * * *$ & -5.1 to -3.5 & cons & $-6.56 * * *$ & $-6.56^{* * *}$ & -7.8 to -5.3 \\
\hline $\begin{array}{l}\text { Pseudomonas } \\
\text { colonization } j\end{array}$ & & & & $\begin{array}{l}\text { Acinetobacter } \\
\text { colonization } \mathrm{k}\end{array}$ & & & \\
\hline TAP & $-0.71^{* * *}$ & $-0.45^{* * *}$ & -0.71 to -0.2 & TAP & $-0.69 * *$ & -0.43 & -1.1 to 0.0 \\
\hline year & $-0.15 *$ & -0.18 ** & -0.31 to -0.1 & year & 0.17 & 0.17 & -0.12 to 0.4 \\
\hline $\operatorname{los} 5$ & $0.99 *$ & 0.51 & -0.20 to 1.2 & $\operatorname{los} 5$ & 0.76 & 0.34 & -0.4 to 1.3 \\
\hline $\operatorname{los} 10$ & $0.51 * * *$ & $0.52 * * *$ & 0.28 to 0.7 & $\operatorname{los} 10$ & $0.94^{* * *}$ & $0.91 * * *$ & 0.46 to 1.3 \\
\hline trauma & -0.14 & -0.13 & -0.47 to 0.2 & trauma & 0.44 & 0.4 & -0.03 to 0.95 \\
\hline Anti-septic & $-0.77^{* * *}$ & -0.28 & -0.77 to 0.2 & Anti-septic & $-1.09 * *$ & -0.59 & -1.5 to 0.1 \\
\hline $\mathrm{crf}$ & 0.26 & -0.46 & -1.2 to 0.2 & $\mathrm{crf}$ & -0.27 & -0.95 & -3.1 to 1.2 \\
\hline $\begin{array}{c}\text { Candida colonization }{ }^{1} \\
\text { b_can_n }\end{array}$ & - & $0.33^{* * *}$ & 0.22 to 0.45 & $\begin{array}{c}\text { Candida colonization }{ }^{1} \\
\text { b_can_n }\end{array}$ & - & $0.32 *$ & 0.01 to 0.5 \\
\hline Candida colonization ${ }^{1}$ & $0.50 * * *$ & $0.48^{* * *}$ & 0.3 to 0.64 & Candida colonization ${ }^{1}$ & $0.49 * * *$ & $0.49^{* * *}$ & 0.3 to 0.67 \\
\hline _cons & $-5.62 * * *$ & $-5.66^{* * *}$ & -6.2 to -5.1 & _cons & $-5.62 * * *$ & $-5.56^{* * *}$ & -6.1 to -4.9 \\
\hline $\mathrm{v} \_$can_n & & & & $\mathrm{v}_{-} \mathrm{can} \_\mathrm{n}$ & & & \\
\hline Candida colonization ${ }^{1}$ & 1 & 1 & (constrained) & Candida colonization ${ }^{1}$ & 1 & 1 & (constrained) \\
\hline mvp90 & 0.02 & 0.31 & -0.53 to 1.1 & mvp90 & 0.02 & 0.12 & -0.80 to 0.89 \\
\hline non_D & -0.28 & -0.43 & -1.1 to 0.21 & non_D & -0.28 & -0.27 & -0.97 to 0.38 \\
\hline cons & $-6.53 * * *$ & $-6.86^{* * *}$ & -8.4 to -5.3 & cons & $-6.53 * * *$ & $-6.51 * * *$ & -8.1 to -4.9 \\
\hline Candida colonization ${ }^{1}$ & & & & Candida colonization ${ }^{1}$ & & & \\
\hline TAP & 0.64 & 0.54 & -0.31 to 1.4 & TAP & 0.64 & 0.64 & -0.22 to 1.5 \\
\hline year & -0.01 & 0.08 & -0.26 to 0.4 & year & -0.01 & -0.02 & -0.36 to 0.28 \\
\hline $\operatorname{los} 5$ & $1.62 * *$ & $1.59 * *$ & 0.62 to 2.7 & $\operatorname{los} 5$ & $1.62 * *$ & $1.55 * *$ & 0.51 to 2.7 \\
\hline $\operatorname{los} 10$ & -0.09 & -0.13 & -0.59 to 0.4 & $\operatorname{los} 10$ & -0.09 & -0.08 & -0.55 to 0.5 \\
\hline trauma & 0.19 & 0.05 & -0.9 to 0.9 & trauma & 0.19 & 0.16 & -0.83 to 0.99 \\
\hline Anti-septic & -1.44 ** & $-1.47^{* *}$ & -2.4 to -0.6 & Anti-septic & -1.44 ** & $-1.39 * *$ & -2.4 to -0.5 \\
\hline Anti-fungal & $-1.58^{* * *}$ & $-1.6 * * *$ & -2.5 to -0.72 & Anti-fungal & $-1.58 * * *$ & $-1.6^{* * *}$ & -2.5 to -0.69 \\
\hline crf & $2.10^{* * *}$ & $2.25^{* * *}$ & 1.2 to 3.3 & crf & $2.10^{* * *}$ & $2.16^{* * *}$ & 1.05 to 3.1 \\
\hline Error terms & & & & Error terms & & & \\
\hline $\begin{array}{l}\text { var (e. Candida } \\
\text { colonization) }\end{array}$ & $1.49^{* * *}$ & $1.49^{* * *}$ & 1.0 to 2.3 & $\begin{array}{l}\text { var (e. Candida } \\
\text { colonization) }\end{array}$ & $1.49^{* * *}$ & $1.47^{* * *}$ & 1.0 to 2.3 \\
\hline $\begin{array}{l}\text { var (e. Pseudomonas } \\
\text { colonization) }\end{array}$ & $0.46^{* * *}$ & $0.30^{* * *}$ & 0.20 to 0.44 & $\begin{array}{l}\text { var (e. Acinetobacter } \\
\text { colonization) }\end{array}$ & $1.42^{* * *}$ & $1.27^{* * *}$ & 0.95 to 1.7 \\
\hline Model fit $\mathrm{m}$ & & & & Model fit ${ }^{m}$ & & & \\
\hline AIC & 3631.39 & 3600.45 & - & AIC & 2723.04 & 2717.31 & - \\
\hline Groups (n) & 439 & 439 & - & Groups (n) & 395 & 395 & - \\
\hline Clusters (n) & 276 & 276 & & Clusters (n) & 247 & 247 & - \\
\hline Factors & 30 & 31 & - & Factors & 30 & 31 & - \\
\hline
\end{tabular}

${ }^{\mathrm{a}}$. Legend: ${ }^{*} p<0.05 ;{ }^{* *} p<0.01 ;{ }^{* * *} p<0.001{ }^{\mathrm{b}}$. Shown in this table are models derived with all studies (models $1,2,5$ and 6). ${ }^{c}$. Models derived after excluding studies with $\operatorname{LOS}<5$ days (models $3,4,7$ and 8 ) are shown in the ESM (ESM Tables S6 and S7). The figures corresponding to models 1 (Figure S5a), model 2 (Figure 1 and ESM Figure S5b), model 5 (ESM Figure S7a) and Model 6 (ESM Figure S7b). d. Abbreviations; v_ps_n is the count of Pseudomonas VAP; ${ }^{\mathrm{e}}$. $\mathrm{v} \_\mathrm{ac} \_\mathrm{n}$ is the count of Acinetobacter VAP; ${ }^{\mathrm{f}}$. $\mathrm{v} \_$can $\_\mathrm{n}$ is the count of $R T$ Candida; $\mathrm{g}$. $\mathrm{b} \_\mathrm{ps} \_\mathrm{n}$ is the count of Pseudomonas bacteraemia and ${ }^{\mathrm{h}}$. $\mathrm{b} \_\mathrm{ac} \_\mathrm{n}$ is the count of Acinetobacter bacteraemia; ${ }^{\mathrm{i}}$. b_can_n is the count of Candidemia; VAP is ventilator-associated pneumonia; non-D is non-decontamination, A_s is anti-septic; $\mathrm{Ab}$ is antibiotic control group; TAP is topical antibiotic prophylaxis. PPAP is the group wide use of protocolized parenteral antibiotic prophylaxis; tap is topical antibiotic prophylaxis; non-D is a non-decontamination intervention; year = year of study publication in units of ten (decade). MVP90 is use of mechanical ventilation by more than $90 \%$ of the group. Crf is group wide exposure to a candidemia risk factor. LOS5 is a mean or median length of ICU stay for the group of less than 5 days. LOS10 is a mean or median length of ICU stay for the group of more than 10 days. Trauma ICU arbitrarily defined as an ICU for which $>50 \%$ of admissions were for trauma. ${ }^{j}$. Pseudomonas colonization (Pseudomonas col) is a latent variable. ${ }^{\mathrm{k}}$. Acinetobacter colonization (Acinteobacter col) is a latent variable. ${ }^{1}$. Candida colonization (Candida col) is a latent variable. ${ }^{\mathrm{m}}$. Model fit; AIC is Akaike's information criteria. This indicates model fit taking into account the statistical goodness of fit and the number of parameters in the model. Lower values of AIC indicate a better model fit. Groups is the number of patient groups; clusters is the number of studies; $\mathrm{N}$ is the number of parameters in the model. 


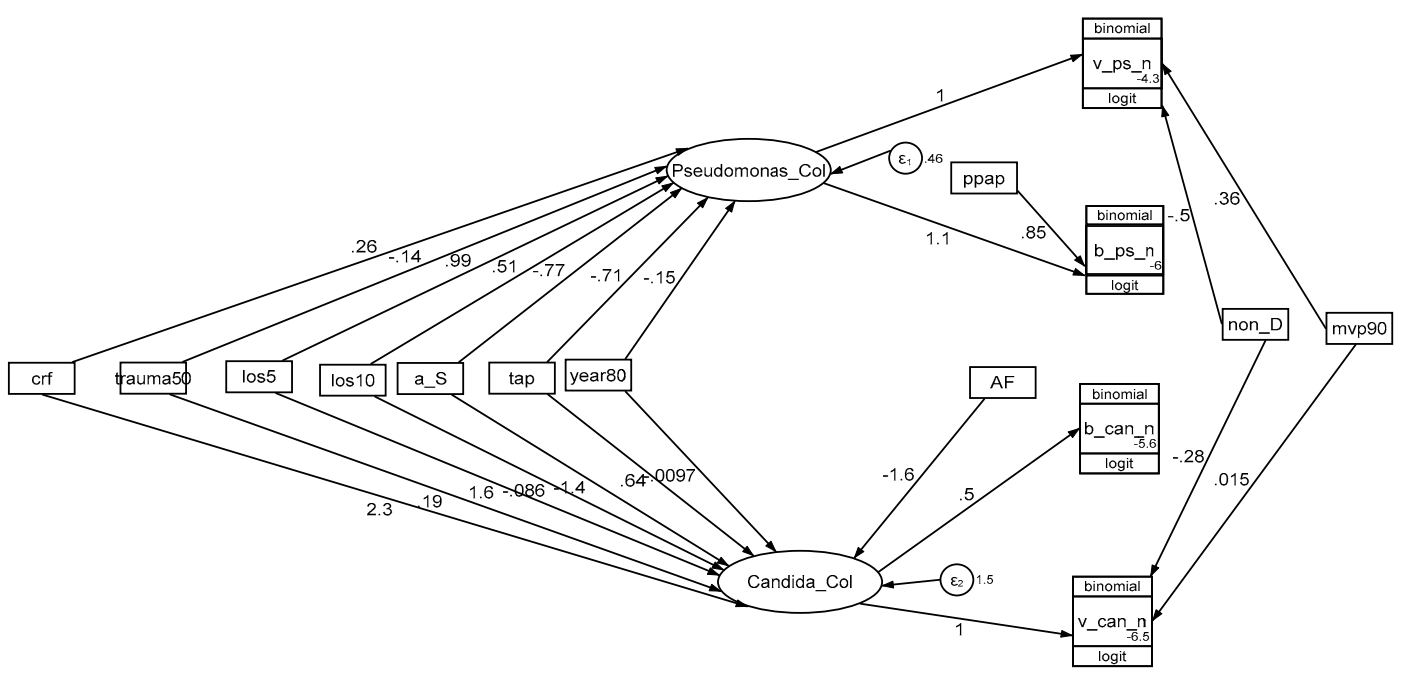

(a)

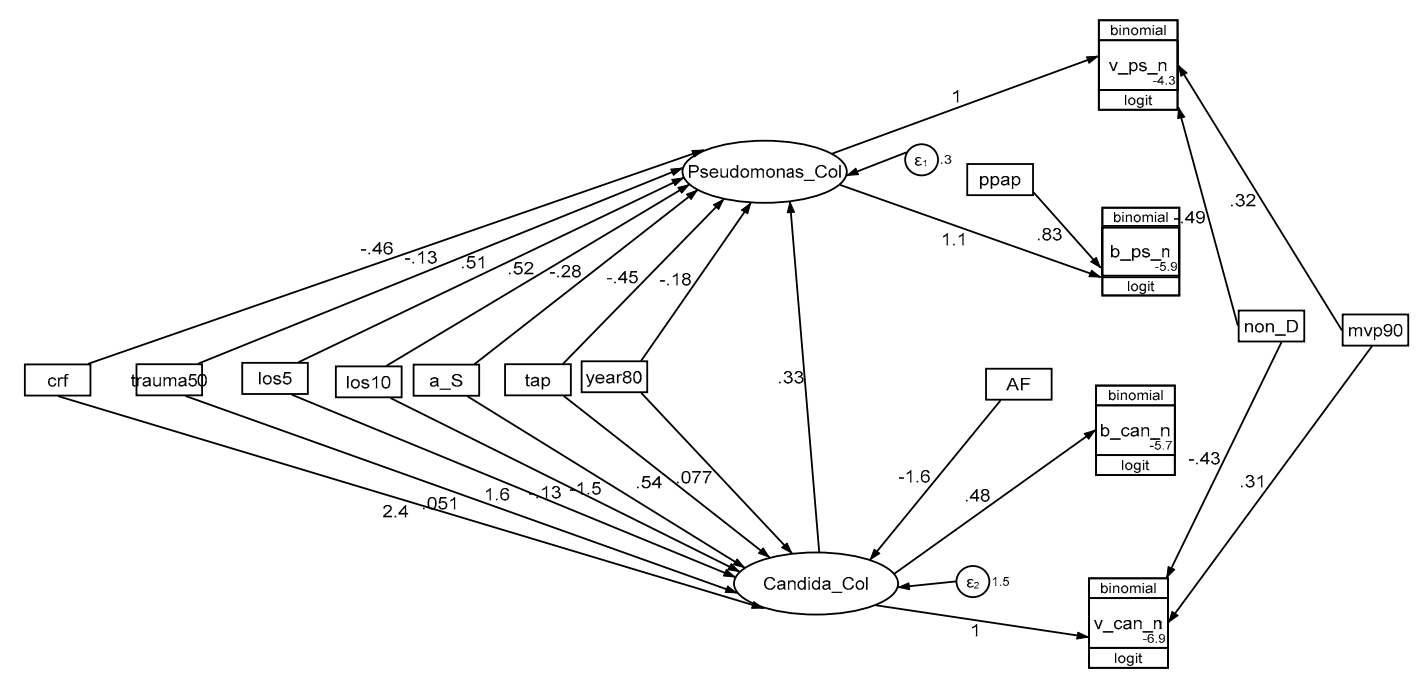

(b)

Figure 5. A GSEM founded on CAPI concepts without (a, model 1) and with (b, model 2) an interaction term between Pseudomonas colonization and Candida colonization. The model including in interaction term (model 2) is optimal. Candida_col, and Pseudomonas_col (ovals) are latent variables representing Candida, and Pseudomonas colonization, respectively. The variables in rectangles are binary predictor variables representing the group-level exposure to the following; a trauma ICU setting (trauma50), mean or median length of ICU stay $<5$ days (los5), mean or median length of ICU stay $\geq 10$ days (los10), year of study publication (year80), exposure to a topical anti-septic based prevention method (a_S), exposure to an anti-fungal based prevention method (AF), exposure to a TAP based prevention method (tap), exposure to a non-decontamination based prevention method (non-D), use of mechanical ventilation more for than $90 \%$ of the group (mvp90) or exposure to PPAP (ppap). The circles contain error terms $(\varepsilon)$ associated with the latent variables. The three-part boxes represent the count data for Candida, and Pseudomonas VAP (v_can_n, v_ps_n) and bacteraemia (b_can_n, b_ps_n) which are each logit transformed with the total number of patients in each group as the denominator using the logit link function in the generalized model of the GSEM. Corresponding models (Models 3 to 8) for Acinetobacter colonization and models excluding studies with LOS $<5$ days are shown in the ESM (Figures S5-S8). 
In the optimal model for Pseudomonas infection (Table 2, Figure 5), the following exposures; TAP, mean ICU-LOS $>10$ days and the interaction term with Candida colonization, displayed the strongest associations with Pseudomonas colonization. Exposure to PPAP displayed a strong positive association with Pseudomonas bacteraemia counts and exposure to non-decontamination interventions a strong negative association with Pseudomonas VAP counts.

In the optimal model for Acinetobacter infection (Table 2, ESM Figure S7), the following exposures; mean ICU-LOS $>10$ days and the interaction term with Candida colonization displayed the strongest associations with Acinetobacter colonization but the term for exposure to TAP was non-significant.

In all models, exposure to candidemia risk factors, anti-septic, and antifungal interventions displayed strong and consistent associations with Candida colonization. Other exposures were not consistently strong or significant in association with any of the three latent variables or with the infection data.

\section{Discussion}

There are multiple obstacles to defining the clinical relevance of the postulated CAPI model. Candida colonization has several predictors [35] some of which, such as prolonged antibiotic exposure, have broad effects on the microbiome. Candida [5] and bacterial colonization are problematic to define. How the interaction between Candida and bacteria might enhance the infection potential of either is likely more complex than simply co-location within the microbiome [4]. VAP is an imprecise endpoint. Bacteraemia with Pseudomonas and Acinetobacter are each uncommon, as is candidemia. Finally, data derived from concurrent control and intervention groups from single center clinical studies will exhibit dependency, especially so for infectious disease data.

Presumably as a result of these obstacles, attempts to validate the CAPI model have reported conflicting results. On the one hand, there is some evidence that the risk of VAP in association with Pseudomonas aeruginosa is more common in patients colonized by C. albicans [36] and that antifungal treatments can reduce this likelihood [37]. One study found that Candida colonization of the respiratory tract is associated with Acinetobacter VAP but not Pseudomonas VAP [38].

On the other hand, several attempts to address the CAPI model though either retrospective studies of the association with anti-fungal use or through studies of either pre-emptive or intensified prophylactic anti-fungal treatment [39-41] have failed to resolve the question. Several have questioned the specificity of the association and whether any association is simply a reflection of confounding by illness severity [42] or may depend on altered immune responses [43]. Even multi-centre studies may be underpowered to show differences for Pseudomonas bacteraemia, and more so Acinetobacter bacteraemia, being rare end points with benchmark incidences of $1.2 \%$ and $0.6 \%$, respectively. An adequately powered study of these end points as a cluster randomized study would require $>100,000$ patients [44]. Moreover, they may be confounded by the geographic variation in the incidences of Pseudomonas VAP [45], and more so Acinetobacter VAP [46].

The approach here is to circumvent these obstacles by using, as a natural experiment, data from $>400$ patient groups from $>250$ studies of infection prevention interventions among ICU patients. The various groups of these studies have been exposed to infection prevention interventions which, in conjunction with other exposures, modify the patient microbiome. Of note, any one group here could experience multiple concurrent exposures such as concomitant CRF, TAP, PPAP, anti-fungal and ICU-LOS $>10$ days. This is reflected in the wide range in incidences of infections across the $>400$ groups. Moreover, membership of a concurrent control group within a study of TAP is associated with significant one percentage point higher incidences of both candidemia [29] and also Candida as a respiratory tract isolate [28] in comparison to comparable patient groups in the literature.

The findings here recapitulate the findings from earlier analyses of these studies which demonstrated support for the concept that the control of gut overgrowth with Acinetobacter and Pseudomonas is key in the mediation of the effects of TAP based decontamination [27]. The analysis here 
includes in addition Candida infection data from these studies and also studies of single anti-fungal prophylaxis against invasive Candida infections.

SEM is emerging as a method in critical care research to model the relationships among multiple simultaneously observed variables in order to provide a quantitative test of any theoretical model proposed within the literature [33]. An ability to test the validity and inferred relationship of conceptual variables that cannot be directly quantified is achieved by using latent variables within the model. GSEM allows generalized linear response functions in addition to the linear response functions allowed by SEM.

The GSEM analysis takes a structural rather than statistical approach to the CAPI question. The structural approach means that a limited number of conceptually key group-level factors were entered as simple binary variables into intentionally simplistic GSEM models. There was no ability nor purpose to adjust for the underlying patient level risk. The true relationships between exposures and outcomes will likely be centre specific, complex, graded and with multiple exposure interactions. Specifically, the association coefficients for the three broad categories of anti-fungal, anti-septic and topical antibiotic based infection prevention interventions derived here may not reflect the magnitude of their true effect size within an optimally designed study. A statistical approach would use more conventional analytic methods such as meta-analysis which, being based on an assumption of exchangeability between control and intervention groups that randomized assignment of exposures provides, allows more precise effect size estimates for specific individual interventions.

\section{Limitations}

There are five key limitations to this analysis, the first being that this analysis is a group-level modelling of three latent variables, Candida colonization, Pseudomonas colonization and Acinetobacter colonization. These latent variables are defined in each GSEM model but the derived coefficients are indicative and intended for internal reference only. They have no counterpart at the level of any one patient or study. Specifically, they are not estimates of colonization that might be measured by conventional methods at any one body site.

The second limitation is that there was considerable heterogeneity in the interventions, populations, and study designs among the studies here as the inclusion criteria for the various studies have been intentionally broadly specified. This breadth is both a strength, in that the breadth of the group wide exposures is the basis for the natural experiment here, and a limitation, in that the associations for a group wide exposure may not equate to associations at the level of an individual patient exposure.

Thirdly, several assumptions have been made for studies that failed to report key exposure and outcome variables in the analysis. For example, missing data for ICU-LOS and percent receiving MV has been broadly imputed. The extracted data are drawn mostly from studies located in systematic reviews and is provided in sufficient detail in the ESM to enable replication of the analysis.

Fourth, there are a large number of studies not included here because the required infection count data was not reported. However, the differences between control and intervention group mean Acinetobacter and Pseudomonas infection incidences noted here are similar to the summary effect sizes for each of the three broad categories of TAP, anti-septic and non-decontamination methods, against both overall VAP and against overall bacteraemia which in turn are similar to prior published effect estimates sizes seen in systematic reviews of these interventions from which most of the studies examined here were derived [6-26].

Fifth, each category of TAP, anti-septic and anti-fungal intervention include a broad range of specific interventions within the various studies. This is a deliberate simplification in the GSEM modelling as some, for example, the anti-fungal regimens, targeted different body sites. Additionally, the duration of application of the regimens varied among the studies.

A strength of this analysis is that it attempts to unpack the separate associations between the Acinetobacter and Pseudomonas infection incidences and the variable exposure to the various SDD components (TAP, PPAP, anti-fungal). As previously noted, PPAP displays a strong positive association 
with Pseudomonas bacteraemia [27]. This is possibly not paradoxical as antibiotics used for PPAP typically lack activity against Pseudomonas and Acinetobacter. In this regard, the cumulative days of exposure to antibiotics without activity against Pseudomonas has been reported as being a risk factor for acquiring Pseudomonas and Acinetobacter in the ICU [47-50].

Another strength is that the results of the model is robust to the inclusion of groups with ICU-LOS $<5$ days in a sensitivity test. These groups are of interest because of the increasing focus on ICU patient groups with a shorter overall length of stay. Likewise, whether patients receiving MV are the optimal patient group to target for decontamination is unclear and the analysis here is not limited to the MV patient group.

\section{Conclusions}

GSEM modelling of Pseudomonas, Acinetobacter and Candida colonization, each as latent variables, versus group-level exposures, provide support to the CAPI concept. The magnitude of the interaction between Candida colonization with indices of infections arising from Acinetobacter and Pseudomonas colonization could be as large as the association of these indices with TAP exposure. The CAPI interactions could explain the observed infection incidences being higher among the groups of TAP studies and the TAP interventions being paradoxically without effect against Pseudomonas VAP [51]. These observations raise further concerns about the safety of TAP as an infection prevention method used within the ICU context [52-55].

Supplementary Materials: The following are available online at http://www.mdpi.com/2309-608X/6/4/252/s1, Table S1: Observational studies (Benchmark groups); Table S2: Groups of non-decontamination studies; Table S3: Groups of anti-septic studies; Table S4: Groups of TAP studies; Table S5: Groups from anti-fungal studies; Table S6: Development of Pseudomonas GSEM models (models 1-4); Table S7: Development of Acinetobacter GSEM models (models 5-8); Supplementary References; Figure S1. Search, screening, triage and decant of studies and groups; Figure S2a,b. Candidemia and RT Candida count data; Figure S3a,b. Pseudomonas; VAP and bacteraemia count data; Figure S4a,b. Acinetobacter; VAP and bacteraemia count data; Figure S5a,b. Pseudomonas GSEM models 1 and 2 (all studies); Figure S6a,b. Pseudomonas GSEM models 3 and 4; (Excluding studies with ICU-LOS $<5$ days); Figure S7a,b. Acinetobacter GSEM models 5 and 6 (all studies); Figure S8a,b. Acinetobacter GSEM models 5 and 6.

Author Contributions: As sole author, J.C.H. produced the design of the study, performed the statistical analysis and wrote the manuscript. J.C.H. read and approved the final manuscript and is the guarantor of the paper. All authors have read and agreed to the published version of the manuscript.

Funding: This research has been supported by the Australian Government Department of Health and Ageing through the Rural Clinical Training and Support (RCTS) program.

Conflicts of Interest: The author declares that he has no competing interests. The funders had no role in the design of the study; in the collection, analyses, or interpretation of data; in the writing of the manuscript, or in the decision to publish the results.

\section{References}

1. Huang, D.; Qi, M.; Hu, Y.; Yu, M.; Liang, Z. The impact of Candida spp airway colonization on clinical outcomes in patients with ventilator-associated pneumonia: A systematic review and meta-analysis. Am. J. Infect. Control. 2020. [CrossRef]

2. Meersseman, W.; Lagrou, K.; Spriet, I.; Maertens, J.; Verbeken, E.; Peetermans, W.E.; Wijngaerden, E.V. Significance of the isolation of Candida species from airway samples in critically ill patients: A prospective, autopsy study. Intensive Care Med. 2009, 35, 1526-1531. [CrossRef]

3. Wood, G.C.; Mueller, E.W.; Croce, M.A.; Boucher, B.A.; Fabian, T.C. Candida spp isolated from bronchoalveolar lavage: Clinical significance in critically ill trauma patients. Intensive Care Med. 2006, 32, 599-603. [CrossRef]

4. Pendleton, K.M.; Huffnagle, G.B.; Dickson, R.P. The significance of Candida in the human respiratory tract: Our evolving understanding. Pathog. Dis. 2017, 75, 29. [CrossRef] [PubMed]

5. Eggimann, P.; Pittet, D. Candida colonization index and subsequent infection in critically ill surgical patients: 20 years later. Intensive Care Med. 2014, 40, 1429-1448. [CrossRef] [PubMed] 
6. Liberati, A.; D'Amico, R.; Pifferi, S.; Torri, V.; Brazzi, L.; Parmelli, E. Antibiotic prophylaxis to reduce respiratory tract infections and mortality in adults receiving intensive care (Review). Cochrane Database Syst. Rev. 2009, 4, 22.

7. Pileggi, C.; Bianco, A.; Flotta, D.; Nobile, C.G.; Pavia, M. Prevention of ventilator-associated pneumonia, mortality and all intensive care unit acquired infections by topically applied antimicrobial or antiseptic agents: A meta-analysis of randomized controlled trials in intensive care units. Crit. Care 2011, 15, 155. [CrossRef] [PubMed]

8. Silvestri, L.; Van Saene, H.K.; Casarin, A.; Berlot, G.; Gullo, A. Impact of selective decontamination of the digestive tract on carriage and infection due to Gram-negative and Gram-positive bacteria: A systematic review of randomised controlled trials. Anaesth. Intensive Care 2008, 36, 324-338. [CrossRef]

9. Hurley, J.C. Prophylaxis with enteral antibiotics in ventilated patients: Selective decontamination or selective cross-infection? Antimicrob. Agents Chemother. 1995, 39, 941-947. [CrossRef] [PubMed]

10. Silvestri, L.; Van Saene, H.K.; Milanese, M.; Gregori, D.; Gullo, A. Selective decontamination of the digestive tract reduces bacterial bloodstream infection and mortality in critically ill patients. Systematic review of randomized, controlled trials. J. Hosp. Infect. 2007, 65, 187-203. [CrossRef] [PubMed]

11. Silvestri, L.; Weir, W.I.; Gregori, D.; Taylor, N.; Zandstra, D.F.; van Saene, J.J.; van Saene, H.K. Impact of Oral Chlorhexidine on Bloodstream Infection in Critically Ill Patients: Systematic Review and Meta-Analysis of Randomized Controlled Trials. J. Cardiothorac. Vasc. Anesth. 2017, 31, 2236-2244. [CrossRef]

12. Klompas, M.; Speck, K.; Howell, M.D.; Greene, L.R.; Berenholtz, S.M. Reappraisal of routine oral care with chlorhexidine gluconate for patients receiving mechanical ventilation: Systematic review and meta-analysis. Intern. Med. 2014, 174, 751-761. [CrossRef]

13. Alhazzani, W.; Smith, O.; Muscedere, J.; Medd, J.; Cook, D. Toothbrushing for Critically Ill Mechanically Ventilated Patients: A Systematic Review and Meta-Analysis of Randomized Trials Evaluating Ventilator-Associated Pneumonia. Crit. Care Med. 2013, 41, 646-655. [CrossRef] [PubMed]

14. Messori, A.; Trippoli, S.; Vaiani, M.; Gorini, M.; Corrado, A. Bleeding and pneumonia in intensive care patients given ranitidine and sucralfate for prevention of stress ulcer: Meta-analysis of randomised controlled trials. BMJ 2000, 321, 1103-1106. [CrossRef] [PubMed]

15. Huang, J.; Cao, Y.; Liao, C.; Wu, L.; Gao, F. Effect of histamine-2-receptor antagonists versus sucralfate on stress ulcer prophylaxis in mechanically ventilated patients: A meta-analysis of 10 randomized controlled trials. Crit. Care 2010, 14, 194. [CrossRef] [PubMed]

16. Alhazzani, W.; Almasoud, A.; Jaeschke, R.; Lo, B.W.; Sindi, A.; Altayyar, S.; Fox-Robichaud, A. Small bowel feeding and risk of pneumonia in adult critically ill patients: A systematic review and meta-analysis of randomized trials. Crit. Care 2013, 17, 127. [CrossRef] [PubMed]

17. Melsen, W.G.; Rovers, M.M.; Bonten, M.J.M. Ventilator-associated pneumonia and mortality: A systematic review of observational studies. Crit. Care Med. 2009, 37, 2709-2718.

18. Safdar, N.; Dezfulian, C.; Collard, H.R.; Saint, S. Clinical and economic consequences of ventilator-associated pneumonia: A systematic review. Crit. Care Med. 2005, 33, 2184-2193. [CrossRef]

19. Han, J.; Liu, Y. Effect of ventilator circuit changes on ventilator-associated pneumonia: A systematic review and meta-analysis. Respir. Care 2010, 55, 467-474.

20. Subirana, M.; Solà, I.; Benito, S. Closed tracheal suction systems versus open tracheal suction systems for mechanically ventilated adult patients. Cochrane Database Syst. Rev. 2007, 4, 4581. [CrossRef]

21. Siempos, I.I.; Vardakas, K.Z.; Kopterides, P.; Falagas, M.E. Impact of passive humidification on clinical outcomes of mechanically ventilated patients: A meta-analysis of randomized controlled trials. Crit. Care Med. 2007, 35, 2843-2851.

22. Muscedere, J.; Rewa, O.; McKechnie, K.; Jiang, X.; Laporta, D.; Heyland, D.K. Subglottic secretion drainage for the prevention of ventilator-associated pneumonia: A systematic review and meta-analysis. Crit. Care Med. 2011, 39, 1985-1991. [CrossRef]

23. Delaney, A.; Gray, H.; Laupland, K.B.; Zuege, D.J. Kinetic bed therapy to prevent nosocomial pneumonia in mechanically ventilated patients: A systematic review and meta-analysis. Crit. Care 2006, 10, 70. [CrossRef]

24. Sud, S.; Friedrich, J.O.; Taccone, P.; Polli, F.; Adhikari, N.K.; Latini, R.; Gattinoni, L. Prone ventilation reduces mortality in patients with acute respiratory failure and severe hypoxemia: Systematic review and meta-analysis. Intensive Care Med. 2010, 36, 585-599. [CrossRef] 
25. Siempos, I.I.; Vardakas, K.Z.; Falagas, M.E. Closed tracheal suction systems for prevention of ventilator-associated pneumonia. Br. J. Anaesth. 2008, 100, 299-306. [CrossRef]

26. Silvestri, L.; Miguel, A.; van Saene, H.K. Selective decontamination of the digestive tract: The mechanism of action is control of gut overgrowth. Intensive Care Med. 2012, 38, 1738-1750. [CrossRef]

27. Hurley, J.C. Structural equation modelling the 'control of gut overgrowth' in the prevention of ICU acquired Gram-negative infection. Crit. Care 2020, 24, 189. [CrossRef]

28. Hurley, J.C. Impact of selective digestive decontamination on respiratory tract Candida among patients with suspected ventilator-associated pneumonia. A meta-analysis. Eur. J. Clin. Microbiol. Infect. Dis. 2016, 35, 1121-1135. [CrossRef]

29. Hurley, J.C. ICU-acquired candidemia within selective digestive decontamination studies: A meta-analysis. Intensive Care Med. 2015, 41, 1877-1885. [CrossRef]

30. Hurley, J.C. Paradoxical Acinetobacter-associated ventilator-associated pneumonia incidence rates within prevention studies using respiratory tract applications of topical polymyxin: Benchmarking the evidence base. J. Hosp. Infect. 2018, 100, 105-113. [CrossRef]

31. Hurley, J.C. Unusually high incidences of Pseudomonas bacteremias within topical polymyxin-based decolonization studies of mechanically ventilated patients: Benchmarking the literature. Open Forum Infect. Dis. 2018, 5, 256. [CrossRef] [PubMed]

32. Goodman, L.A. Snowball sampling. Ann. Math. Stat. 1961, 32, 148-170. [CrossRef]

33. Stata Corporation. Stata Structural Equation Modelling Reference Manual, in Stata 16 Documentation. College Station, TX, USA. Available online: https://www.stata.com/bookstore/structural-equation-modelingreference-manual/ (accessed on 6 January 2020).

34. Huang, S.S.; Septimus, E.; Kleinman, K.; Moody, J.; Hickok, J.; Avery, T.R.; Lankiewicz, J.; Gombosev, A.; Terpstra, L.; Hartford, F.; et al. Targeted versus universal decolonization to prevent ICU infection. N. Engl. J. Med. 2013, 368, 2255-2265. [CrossRef]

35. León, C.; Ostrosky-Zeichner, L.; Schuster, M. What's new in the clinical and diagnostic management of invasive candidiasis in critically ill patients? Intensive Care Med. 2014, 40, 808-819. [CrossRef]

36. Azoulay, E.; Timsit, J.F.; Tafflet, M.; de Lassence, A.; Darmon, M.; Zahar, J.R.; Adrie, C.; Garrouste-Orgeas, M.; Cohen, Y.; Mourvillier, B.; et al. Candida colonization of the respiratory tract and subsequent Pseudomonas ventilator-associated pneumonia. Chest 2006, 129, 110-117. [CrossRef]

37. Nseir, S.; Jozefowicz, E.; Cavestri, B.; Sendid, B.; Di Pompeo, C.; Dewavrin, F.; Favory, R.; Roussel-Delvallez, M.; Durocher, A. Impact of antifungal treatment on Candida-Pseudomonas interaction: A preliminary retrospective case-control study. Intensive Care Med. 2007, 33, 137-142. [CrossRef]

38. Tan, X.; Zhu, S.; Yan, D.; Chen, W.; Chen, R.; Zou, J.; Yan, J.; Zhang, X.; Farmakiotis, D.; Mylonakis, E. Candida spp. airway colonization: A potential risk factor for Acinetobacter baumannii ventilator-associated pneumonia. Med. Mycol. 2016, 21, 557-566. [CrossRef]

39. Albert, M.; Williamson, D.; Muscedere, J.; Lauzier, F.; Rotstein, C.; Kanji, S.; Jiang, X.; Hall, M.; Heyland, D. Candida in the respiratory tract secretions of critically ill patients and the impact of antifungal treatment: A randomized placebo controlled pilot trial (CANTREAT study). Intensive Care Med. 2014, 40, 1313-1322. [CrossRef]

40. Ong, D.S.; Klouwenberg, P.M.; Spitoni, C.; Bonten, M.J.; Cremer, O.L. Nebulised amphotericin B to eradicate Candida colonisation from the respiratory tract in critically ill patients receiving selective digestive decontamination: A cohort study. Crit. Care 2013, 17, R233. [CrossRef]

41. Lindau, S.; Nadermann, M.; Ackermann, H.; Bingold, T.M.; Stephan, C.; Kempf, V.A.; Herzberger, P.; Beiras-Fernandez, A.; Zacharowski, K.; Meybohm, P. Antifungal therapy in patients with pulmonary Candida spp. colonization may have no beneficial effects. J. Intensive Care 2015, 3, 31. [CrossRef]

42. Terraneo, S.; Ferrer, M.; Martin-Loeches, I.; Esperatti, M.; Di Pasquale, M.; Giunta, V.; Rinaudo, M.; de Rosa, F.; Bassi, G.L.; Centanni, S.; et al. Impact of Candida spp. isolation in the respiratory tract in patients with intensive care unit-acquired pneumonia. Clin. Microbiol. Infect. 2016, 22, 94. [CrossRef] [PubMed]

43. Timsit, J.F.; Schwebel, C.; Styfalova, L.; Cornet, M.; Poirier, P.; Forrestier, C.; Ruckly, S.; Jacob, M.C.; Souweine, B. Impact of bronchial colonization with Candida spp. on the risk of bacterial ventilator-associated pneumonia in the ICU: The FUNGIBACT prospective cohort study. Intensive Care Med. 2019, 45, 834-843. [CrossRef] 
44. Hurley, J.C. How the Cluster randomized trial 'works'. Clin. Infect. Dis. 2020, 70, 341-346. [CrossRef] [PubMed]

45. Hurley, J.C. Worldwide variation in Pseudomonas associated ventilator associated pneumonia. A meta-regression. J. Crit. Care 2019, 51, 88-93. [CrossRef] [PubMed]

46. Hurley, J.C. World-wide variation in incidence of Acinetobacter associated ventilator associated pneumonia: A meta-regression. BMC Infect. Dis. 2016, 16, 577. [CrossRef] [PubMed]

47. Jongerden, I.P.; Speelberg, B.; Satizábal, C.L.; Buiting, A.G.; Leverstein-van Hall, M.A.; Kesecioglu, J.; Bonten, M.J. The role of systemic antibiotics in acquiring respiratory tract colonization with gram-negative bacteria in intensive care patients: A nested cohort study. Crit. Care Med. 2015, 43, 774-780. [CrossRef]

48. Venier, A.G.; Leroyer, C.; Slekovec, C.; Talon, D.; Bertrand, X.; Parer, S.; Alfandari, S.; Guerin, J.M.; Megarbane, B.; Lawrence, C.; et al. Risk factors for Pseudomonas aeruginosa acquisition in intensive care units: A prospective multicentre study. J. Hosp. Infect. 2014, 88, 103-108. [CrossRef]

49. Hoang, S.; Georget, A.; Asselineau, J.; Venier, A.G.; Leroyer, C.; Rogues, A.M.; Thiébaut, R. Risk factors for colonization and infection by Pseudomonas aeruginosa in patients hospitalized in intensive care units in France. PLOS ONE 2018, 13, e0193300. [CrossRef]

50. Medina, J.; Formento, C.; Pontet, J.; Curbelo, A.; Bazet, C.; Gerez, J.; Larrañaga, E. Prospective study of risk factors for ventilator-associated pneumonia caused by Acinetobacter species. J. Crit. Care 2007, 22, 18-26. [CrossRef]

51. Hurley, J.C. Lack of impact of selective digestive decontamination on pseudomonas aeruginosa ventilator-associated pneumonia: Benchmarking the evidence base. J. Antimicrob. Chemother. 2011, 66, 1365-1373. [CrossRef]

52. Hurley, J.C. Discrepancies in control groups mortality rates within studies assessing topical antibiotic strategies to prevent Ventilator-associated Pneumonia. An umbrella review. Crit. Care Explor. 2020, 2, e0076. [CrossRef] [PubMed]

53. Hurley, J.C. Inapparent outbreaks of ventilator-associated pneumonia: An ecological analysis of prevention and cohort studies. Infect. Control Hosp. Epidemiol. 2005, 26, 374-390. [CrossRef] [PubMed]

54. Hurley, J.C. Is selective decontamination (SDD/SOD) safe in the ICU context? J. Antimicrob. Chemother. 2019, 74, 1167-1172. [CrossRef]

55. Hurley, J.C. Antibiotics in the ICU; benefit or harm? Intensive Care Med. 2020, 46, 1798-1799. [CrossRef] [PubMed]

Publisher's Note: MDPI stays neutral with regard to jurisdictional claims in published maps and institutional affiliations.

(C) 2020 by the author. Licensee MDPI, Basel, Switzerland. This article is an open access article distributed under the terms and conditions of the Creative Commons Attribution (CC BY) license (http://creativecommons.org/licenses/by/4.0/). 


\section{University Library}

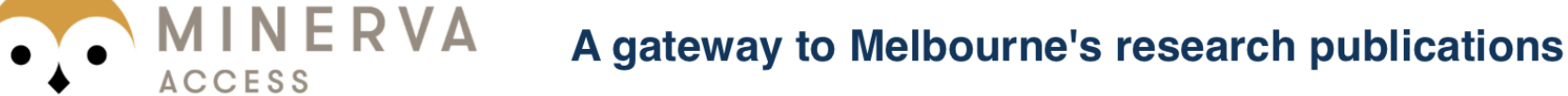

Minerva Access is the Institutional Repository of The University of Melbourne

Author/s:

Hurley, JC

Title:

Candida-Acinetobacter-Pseudomonas Interaction Modelled within 286 ICU Infection Prevention Studies

\section{Date:}

2020-12-01

\section{Citation:}

Hurley, J. C. (2020). Candida-Acinetobacter-Pseudomonas Interaction Modelled within 286 ICU Infection Prevention Studies. JOURNAL OF FUNGI, 6 (4), https://doi.org/10.3390/ jof6040252.

Persistent Link:

http://hdl.handle.net/11343/272039

License:

CC BY 